\title{
Current Aspects of the Endocannabinoid System and Targeted THC and CBD Phytocannabinoids as Potential Therapeutics for Parkinson's and Alzheimer's Diseases: a Review
}

\author{
R. Cooray ${ }^{1,2,3}$ (i) $\cdot$ V. Gupta ${ }^{2} \cdot$ C. Suphioglu ${ }^{1}$ (I)
}

Received: 5 November 2019 / Accepted: 31 July 2020 / Published online: 19 August 2020

(C) The Author(s) 2020

\begin{abstract}
Neurodegeneration leading to Parkinson's disease (PD) and Alzheimer's disease (AD) has become a major health burden globally. Current treatments mainly target controlling symptoms and there are no therapeutics available in clinical practice to preventing the neurodegeneration or inducing neuronal repairing. Thus, the demand of novel research for the two disorders is imperative. This literature review aims to provide a collection of published work on PD and AD and current uses of endocannabinoid system (ECS) as a potential drug target for neurodegeneration. PD is frequently treated with L-DOPA and deep brain stimulation. Recent gene modification and remodelling techniques, such as CRISPR through human embryonic stem cells and induced pluripotent stem cells, have shown promising strategy for personalised medicine. $\mathrm{AD}$ characterised by extracellular deposits of amyloid $\beta$-senile plaques and neurofibrillary tangles of tau protein commonly uses choline acetyltransferase enhancers as therapeutics. The ECS is currently being studied as PD and AD drug targets where overexpression of ECS receptors exerted neuroprotection against PD and reduced neuroinflammation in $\mathrm{AD}$. The delta-9-tetrahydrocannabinoid ( $\Delta^{9}$-THC) and cannabidiol (CBD) cannabinoids of plant Cannabis sativa have shown neuroprotection upon PD and AD animal models yet triggered toxic effects on patients when administered directly. Therefore, understanding the precise molecular cascade following cannabinoid treatment is suggested, focusing especially on gene expression to identify drug targets for preventing and repairing neurodegeneration.
\end{abstract}

Keywords Parkinson's disease $\cdot$ Alzheimer's disease $\cdot$ Endocannabinoid system $\cdot$ THC $\cdot$ CBD

Neurodegenerative disorders (NDDs), characterised by progressive atrophy of nerve cells in both central and peripheral nervous systems, have become a major disease burden not only in lowand middle-income countries (LMICs) but also in the developed world as well. Among all neurodegenerative disorders, 1.8\% account for Parkinson's disease (PD) while Alzheimer's disease (AD) accounts for $12 \%$ with the current rate reporting disease incidences are higher in LMICs [1]. Thus, the demand for novel research for the two disorders is imperative.

\section{R. Cooray}

r.cooray@deakin.edu.au

1 Faculty of Science, Engineering and Built Environment, School of Life and Environmental Sciences, Deakin University, Waurn Ponds, Victoria 3216, Australia

2 Faculty of Health, School of Medicine, Deakin University, Waurn Ponds, Victoria 3216, Australia

3 Section of Genetics, Institute for Research \& Development in Health \& Social Care, Colombo, Sri Lanka
With the emerging studies on determining the pathophysiology of neurodegenerative disorders, the endocannabinoid system (ECS) has drawn a significant attention among researchers due to its potential neuroprotective effects. In this review, the authors aim to provide a collection of published literature of current use of the ECS and its components as a drug target for the most common NDDs, namely PD and AD. The review also discusses the use of external cannabinoids, mainly the THC and CBD, to target ECS in developing therapeutics for the two diseases.

\section{Parkinson's Disease: Current Treatments and Advancements}

Parkinson's disease (PD) is the most prevalent motor disease and second most prevalent NDD [2], characterised by progressive death of dopaminergic neurons, predominantly in substantia nigra pars compacta ( $\mathrm{SNc}$ ), and in neostriatum, and subthalamic nucleus of basal ganglia at low amounts [3]. The intracellular accumulation of Lewy bodies enriched 
in $\alpha$-synuclein protein, and thread-like proteinaceous inclusions called Lewy neuritis, is known to provoke the motor symptoms in PD [4]. The genetic studies describe that the mutations in $\alpha$-synuclein [5, 6], PINK1 [7], DJ-1 (PARK7) $[8,9]$, ubiquitin genes such as ubiquitin-C-hydrolase $[10$, 11], and population-specific gene mutations such as glucocerebrosidase gene in Ashkenazi Jews [12] directly relate to the onset of PD [13]. Evidence suggests that mutations in molecular signalling such as leucine-rich repeat kinase 2 (LRRK2) [14] and Miro GTPases [15] play a vital role in the onset and the progression of PD.

In addition to the L-DOPA, the most commonly used drug for PD, other physiological methods such as deep brain stimulation (DBS) with the basis of Network Centric Therapy are used to control the motor symptoms of PD, such as tremors and stiffness [16]. Furthermore, in attempting hormone therapy, Bourque and colleagues recently reviewed the potential of steroids, especially the sex steroids such as oestrogen and progesterone to be developed as therapy for PD via neurotransmitter modulation of selective brain oestrogen receptors [17]. However, as the authors suggest, an optimised formula should be developed with currently available drugs to specifically target brain receptors. Furthermore, an intervention study by a group of Japanese scientists recently utilised the gene modification and remodelling techniques such as CRISPR through human embryonic stem cells (hESCs) and induced pluripotent stem cells (iPSCs) which showed promising strategy for personalised medicine [18]. The idea, however, requires intensive investigations at a clinical level with a large cohort. The concept of using stem cells has been successfully tested in PD monkey models [19]; however, some level of ethical concern arose when obtaining hESCs at larger amounts for clinical trials. This limitation is addressed by a group of European researchers who initiated a global programme in developing cell-based therapies for PD [20]. The team highlights the challenges to face when developing the stem cell-based therapy such as identifying the most suitable cell line, development of clinical administrable cell product, quality control and quality assurance, pre-clinical testing for accurate dosing, and other measures [20].

Considering the circumstances, further interventions are essential in order to achieve a precise level of control in progression of dopaminergic neurodegeneration. However, to date, no drug has been identified to cease the progression of the neurodegeneration in PD.

\section{Alzheimer's Disease: Current Treatments and Advancements}

As the leading cause of dementia, and the most prevalent NDD, Alzheimer's disease (AD) is characterised by extracellular deposits of amyloid $\beta$-senile plaques and intracellular neurofibrillary tangles composed of hyperphosphorylated tau protein [21], and reduced levels of choline acetyltransferase $[22,23]$. The involvement of-omics in the onset of AD has been popular during the last few years. Four most common genetic mutations responsible for $\mathrm{AD}$ onset have been identified as follows: missense mutation in $\beta$-amyloid precursor protein (APP), ApoE allele mutations, and Presenilin 1 and 2 (PS1\&2) [21]. However, with the recent developments of genome-wide association studies (GWAS), the determination of single-nucleotide polymorphism (SNP) variations has been possible at numerous locations simultaneously, with higher statistical power. Thus, implementing GWAS methods has uncovered several potential genetic mutations, which may not only be responsible for the onset of $\mathrm{AD}$ but also are heritable, with the use of epigenetic studies [24]. Further to the development of bioinformatics tools, analysis of differential gene expression has been attempted for protein-coding and non-coding RNA for AD brain [25]. The study has identified 18 non-coding and 7 protein-coding RNAs in brain tissues and thus their potential of using as a diagnostic marker for AD. Therefore, further transcriptomic studies can be suggested to provide a promising strategy to determine the risk of $\mathrm{AD}$ for penetrative measures and potentially to cease neurodegeneration.

A recent publication reviewed the association of metabolomics in the onset of $\mathrm{AD}$ as it gave an impression on genetics, transcriptomics, proteomics, and environmental factors of the disease [26]. The brain consumes the largest proportion of metabolised glucose for energy generation. However, metabolic impairment and consequence reduction of glucose uptake are commonly seen in AD [26]. All these strategies can immensely be used in the development of novel therapeutics for controlling $\mathrm{AD}$.

Microglia, as the resident immune cells in the central nervous system, is known to play a critical role in brain homeostasis. Being one of the major pathological causes of neurodegeneration, neuro-inflammation induced through microgliopathy has been a popular research theme. Microglia dysfunction leading to neuroinflammation, commonly known as microgliopathy, is a common type of gliosis, associated with several genetic mutations including triggering receptor expressed on myeloid cells-2 (TREM-2). The importance of TREM-2 and related microgliopathy has been widely discussed in several recent reviews due to its significant association with neurodegenerative disorders, primarily in $\mathrm{AD}[27,28]$. The complete knock-out of TREM-2 in AD mice models showed affected microglial activation decreasing the amount of microglia around the plaques [29]; however, the precise mechanism is yet to be understood. Collectively, research evidence the wide role of TREM-2 in reducing microglial cell proliferation [30], microglial survival, increasing apoptosis [31], and microglial autophagy [28, 32]. In addition to TREM-2, the role of other microglia genes such as $C R 1$, SPI1, the MS4As, ABCA7, CD33, and INPP5D has been 
reviewed [33]. The understanding of these microglial genetics in depth as AD risk factors would provide an insight into disease mechanism in deriving therapeutics.

Most common treatments for $\mathrm{AD}$ include inhibitors of acetylcholinesterase (AChE) activity [34,35] such as donepezil, rivastigmine, galantamine [36], and N-methyl-D-aspartate (NMDA) receptor antagonists [37] in the brain. Modulations of the immune system via targeting the specific immune modulators as well as their related genes have been popular in recently published literature [38]. As evidenced in a recent study, the characteristic deprived-expression of toxic proinflammatory M1 microglia genes, CD11b, iNOS, COX-2, and IL1 $\beta$, in $A D$ was restored by using low doses of curcumin in APPsw transgenic mice [39] thus addressing the antiinflammatory property of curcumin on microglia. Recently, using a high dose of monoclonal antibodies targeting $\beta$ amyloid $(\mathrm{A} \beta)$ plaques has been introduced as a therapy [40]. However, these therapeutic advances so far target the control of symptoms, and as yet, no long-term resolution for neurodegeneration or prevention effect of the disease is proven.

\section{The Endocannabinoid System}

Among the many molecular pathways involved in PD and AD pathophysiology, the endocannabinoid system (ECS) has drawn a significant attention in the past decade. With the knowledge that external cannabinoid compounds such as extracted cannabinoids (also known as phytocannabinoids) from the plant Cannabis sativa can act on the brain endocannabinoid system, the development of novel ECStargeted therapeutics has become a popular theme.

The ECS of the central nervous system plays several regulatory functions including cognition, appetite control, and analgesia [41]. The endogenous cannabinoids are presumed to mediate neuronal plasticity via regulation of potentiation, inhibition, and disinhibition of synaptic output, ultimately modulating synaptic functions [42]. Although the exact molecular mechanism is not elucidated, further research will aid our understanding of complex processes involved, including cognitive functions, learning, and memory.

The ECS consists mainly of two primary receptors of family $\mathrm{G}$ protein-coupled receptors (GPCRs): cannabinoid receptors 1 and 2 (CB1R and CB2R), and two primary endogenous cannabinoid (endocannabinoid) neurotransmitters: $\mathrm{N}$ arachidonoyl ethanolamine (AEA), i.e. anandamide [43] and 2-arachidonoyl glycerol (2-AG) [44, 45].

Anandamide is mainly synthesised by catalysing N-acylphosphatidylethanolamine (NAPE) by the catalysing enzyme NAPE-specific phospholipase D (NAPE-PLD) [46] while 2AG is synthesised from diacylglycerol (DAG) by DAG lipase (DAGL) $-\alpha$ or $-\beta$ types, mostly by $-\alpha$ type in adult human brain $[47,48]$. The main enzyme responsible for anandamide degradation is the integral membrane protein fatty acid amide hydrolase (FAAH) which hydrolyses anandamides into free arachidonic acid and ethanolamine [49]. In addition to FAAH [50], 2-AG is mainly hydrolysed by three enzymes in the $\alpha / \beta$ hydrolase superfamily, monoacylglycerol lipase (MAGL), $\alpha /$ $\beta$-hydrolase domain containing 6 (ABHD6) and 12 (ABHD12) [51], to produce arachidonic acid and glycerol [52]. Among the three enzymes, MAGL is well characterised for its structure and function, yet the ABHD6 and ABHD12 remain uncharacterised at molecular level. In addition to enzymatic degradation, they can be degraded by oxidation through cyclooxygenase- 2 and several lipoxygenases [47, $48,53,54]$.

The CB1R, encoded by the gene CNR1, consists of 472 amino acids in humans and found in three different isoforms: one canonical long form (dominates in the brain and skeletal muscles) and two with 33 amino acid deletion at $\mathrm{N}$-terminal (dominant in liver and pancreatic islet cells, i.e. involves in metabolism), whereas CB2R is encoded by the gene CNR2 and consists of 360 amino acids in humans, with only $44 \%$ sequence similarity with CB1R [55]. Among the two isoforms of CB2R identified to the date, one is dominant in the testis and lower levels in brain reward regions, and the other in the spleen and at lower levels in the brain [56]. In addition, CB2R is also observed to express in peripheral tissues such as leukocytes [56] and dendritic cells [57]. Apart from the aforementioned receptors, the endocannabinoids are known to act on non-CB1/CB2 GPCRs. The G protein-coupled receptor 55 (GPR55) expressed in dorsal root ganglion neurons is activated by endocannabinoids such as anandamides as well as phytocannabinoids like as $\Delta^{9}$-THC, and upon activation, may enhance intra-cellular $\mathrm{Ca}^{2+}$ levels [58].

The ECS is evidenced to follow a retrograde signalling, where the endocannabinoids are released from the postsynaptic end and receptors are localised to pre-synapses [48, 59]. The endocannabinoid release can be regulated by calcium influx or calcium-independent pathways [60]. In brief, 2-AG is synthesised in post-synapse and, being lipid messenger, is easily diffused through the membrane into the synaptic cleft towards the pre-synapse in a mechanism which is yet to be elucidated. It activates CB1R in pre-synapse to block signalling neurotransmitter release through suppression of $\mathrm{Ca}^{2+}$ influx via inhibiting voltage-gated $\mathrm{Ca}^{2+}$ channels or by inhibiting cAMP/PKA pathway which inhibits adenylyl cyclase. The 2-AG also identified to activate $\mathrm{CB} 1 \mathrm{R}$ receptors in astrocytes [61]. The cannabinoid signalling is ceased via degradation of 2-AG by monoacylglycerol lipase (MAGL) [48]. Anandamides, on the other hand, diffuse into the synaptic cleft and activate CB1R, or other non-CBRs such as transient receptor potential cation channel subfamily $\mathrm{V}$ member 1 (TRPV1) as a full agonist. Anandamides are also synthesised in pre-synapse yet it is not clear whether they are responsible for anterograde signalling process [48]. 
The ECS and its components have been widely studied in search for therapeutics for PD and AD [62, 63]. The coexpression of CB1R and GPR55 has shown a significant neuroprotection against parkinsonism-inducing $\mathrm{MPP}^{+}$toxin [64]. A similar study was conducted using PC12 cell lines with 6-hydroxydopamine (6-OHDA) neurotoxin-induced PD model treated with anandamide and observed anandamidemediated neuroprotection through preventing apoptosis [65]. Moreover, similar to the effect of anandamide, the 2-AG endocannabinoids have shown neuroprotection against parkinsonism-inducing neurotoxin to prevent cellular apoptosis [66]. Furthermore, anandamide treated in combined noladin ether (2-arachidonyl glyceryl ether) induced similar neuroprotection against $\mathrm{A} \beta$ neurotoxicity in $\mathrm{AD}$ cell lines [67]. However, administration of anandamide and 2-AG in clinical trials requires additional measures and optimisations. Thus, further studies are recommended focusing the strategies to manipulate internal concentrations of endocannabinoids as therapeutics for neuroprotection in PD and AD.

In addition to the endocannabinoid neurotransmitters, the cannabinoid receptors are known to play a vital role in $\mathrm{PD}$ and $\mathrm{AD}$ pathogenesis. The CB1R antagonists, such as rimonabant and MSX-3, independently exerted neuroprotection and enhanced the dopaminergic neuronal survival [68, 69]. It is generally known that the activation of cannabinoid receptors disrupts the neuronal signalling and thus can be used as therapeutics for resting tremor, observed in PD. However, contrastingly, the aforementioned data support that the cannabinoid receptor antagonists can be developed as drugs to treat the hypokinesia, observed in PD by diminishing the CB1R activity.

Although there are only few ECS-targeted studies on Alzheimer's disease models published in the literature, few significant data provided evidence for the potential therapeutic benefit of ECS for AD. One of the studies using AD mouse models compared the CB1R expression levels with the age and concluded that the CB1R expression levels elevate with the age [70]. This can also define as the CB1R levels are increased with the progression of the AD. Another study using $\mathrm{AD}$ rat models injected with $\mathrm{A} \beta$ to induce neurotoxicity has observed activation of CB1R to induce neuroprotective effect on hippocampus CA1 pyramidal neurons via inhibition of voltage-gated $\mathrm{Ca}^{2+}$ channels and suppression of $\mathrm{Ca}^{2+}$-activated $\mathrm{K}^{+}$channels [71]. According to the data, the CB1R but not $\mathrm{CB} 2 \mathrm{R}$ protected against electrophysiological changes such as neuronal firing frequency, induced by the injected $A \beta$. Therefore, although the CB1R expression is promoted in contrast to the formerly mentioned study, the activation of the receptor through $\mathrm{CB} 1 \mathrm{R}$ agonist has exerted neuroprotection. Thus, all the aforementioned results combined emerge the necessity of understanding the interconnected pathways associated with ECS and its components for the development of precise drug targets.
In addition to the endocannabinoid neurotransmitters, the phytocannabinoids act as ligands to the ECS receptors. Among the nearly 60 different cannabinoids identified in the plant Cannabis sativa, cannabidiol (CBD) [72] and delta-9tetrahydrocannabinoid ( $\Delta^{9}$-THC) $[73]$ have been studied intensely for its activity upon PD and AD models in controlling both motor and non-motor symptoms.

A study conducted in the early 1980s with THC-treated reserpine (anti-hypertensive drug)-induced rats evidenced that, though the THC alone does not induce hypokinesia, the THC-reserpine combination produced 20-fold greater hypokinesia [74]. Therefore, the authors warn the excessive use of THC compounds as drug therapeutics for PD. However, recent studies using cell cultures and primate models show positive effects of these external cannabinoids for PD. The PD-induced SH-SY5Y cell cultures were treated with THC and observed direct neuroprotective effect [75]. A research used PD models of marmoset monkeys to treat with THC and observed restoration of the locomotor activities to nearly pre-disease level [73]. The authors hypothesised that this positive effect is due to elevated expression of CB1R in the marmoset PD models. This theory can be supported and validated with the data from a previous study using marmoset models where the PD induced with MPTP, and the animals showed higher concentrations of CB1R expressed in the basal ganglia [76].

Majority of studies attempting to identify the correlation between $\mathrm{CBD}$ and $\mathrm{PD}$ have moved to clinical trials using animal models for behavioural studies [77] and PD patients [78, 79]. However, no studies following long-term effects of CBD administration were identified, nor the studies show permanent cease of neurodegeneration. Therefore, this brings back to the idea that, simultaneously, the knowledge of molecular mechanism is essential in development of therapeutics for effective prevention or cease the neurodegeneration as well as repair process. A study conducted with PC12 cell lines with $\mathrm{MPP}^{+}$induced for PD, when treated with $\mathrm{CBD}$, showed decreased caspase-3 activity thus increases cell viability and also protects against the $\mathrm{MPP}^{+}$-induced cell differentiation inhibition [80]. The study repeated for SH-SY5Y cell lines did not show a similar response to CBD treatment; thus, the authors conclude that the latter may not be a suitable model for the determination of neuroprotective effect of CBD on PD [80]. However, since the SH-SY5Y cell line has shown positive effects for THC, further trials are needed to confirm the suitability of the cell line for CBD based studies.

A recent study of transgenic $\mathrm{Tg}_{4-42}$ mice expressing human $\mathrm{A} \beta_{4-42}$ treated with $\Delta^{9}$-THC showed reduced neuronal loss when compared with the controls [81]. Furthermore, a study used a N2a-variant of amyloid $\beta$ precursor $(\mathrm{A} \beta \mathrm{PP})$ cells treated with THC concluded with a neuroprotective effect exerted on the cells as the THC could significantly decrease the $A \beta$ levels in the cell [82]. The authors also convey that the 
response is time-dependent and that repeated treatments gradually decrease the $A \beta$ synthesis. However, in the study, the THC was administered only twice over the period of $48 \mathrm{~h}$, thus may not have been sufficient to establish a conclusion. Further studies are needed to determine the dose-dependency and time-dependency of potential treatment of cannabinoids to exert a continuous neuroprotective effect and to understand the subsequent ceasing neurodegeneration and neuronal repair. Another study used AD mice models treated with cannabidiol (CBD) over a period of 7 days and observed a significant reduction of $A \beta$ protein expression [83]. Furthermore, a study treated AD mice with CBD daily over the period of 8 months and concluded with contrasting observations that $C B D$ had no effect on soluble and insoluble $A \beta_{40}$ or $A \beta_{42}$ in the cortex and in the hippocampus [84]. These contradictory arguments bring back the need of understanding the precise action of the cannabinoids in the brain prior to therapeutic development and to localise a precise unique target for neurodegeneration. The study, however, describes $\mathrm{CBD}$ as a potential drug for long-term preventative therapy for $\mathrm{AD}$ as the data showed that the CBD treatment had a positive impact on social withdrawal and facial recognition deficits in $\mathrm{AD}$ [84].

Even though the cellular and non-human primate models have shown positive effects for neurodegeneration, the precise molecular mechanism is not well understood. The literature evidenced that the combination of THC-CBD has shown better neuroprotective effect compared with the individual administration of the two compounds $[85,86]$. However, the dosedependency and time-dependency as well as the precise ratio of the safe administrable THC to CBD require the understanding of the molecular mechanism prior to initiating clinical studies. The long-term effects of administrating external compounds such as THC or CBD against natural components, anandamide and 2-AG, are not studied in depth. This identifies the research gap of limited longitudinal observational studies for phytocannabinoids used in PD- and AD-based clinical trials.

This trend of using phytocannabinoids as drug therapeutics for NDDs is followed by the development of synthetic cannabinoids, such as HU-210, JWH-018, and JWH-073 [87]. These synthetic cannabinoid receptor agonists (SCRAs) act on CB1R of the ECS as full agonists and consist mainly of THC, the psychoactive compound rather than $\mathrm{CBD}$, which diminishes the psychoactive properties of THC [87]. As the authors review, initially, the SCRAs have become popular for recreational use as they are not detected by drug testing methods [87]. However, simultaneously, the synthetically developed cannabinoid-based drugs have exerted enhanced positive effects on PD and AD symptom modulation [88]. Further molecular and biochemical studies are essential in determining the potential side effects, especially the long-term adverse effects of the synthetic cannabinoids as drug therapeutics for NDDs. The use of high doses of THC-containing synthetic cannabinoids to act on the ECS component CB1R and its adverse effects are not elucidated. Therefore, the knowledge and understanding of the above will be essential in drug development, especially to avoid neurotoxicity in the neurodegenerated brain.

\section{Regulation of ECS Gene Expression}

The use of the plant Cannabis sativa for medicinal as well as recreational purpose was not uncommon since the early Egyptian era, which was later introduced to Europe and further [59]. However, the emerging adverse effects overtime drew the usage of the plant extracts back, followed by the discovery of the endogenous system of cannabinoids in mammalian brain and its components provoking new hopes in using the ECS as a target for neurological disorders. Pharmacological manipulation and potential of regulation of the gene expression of ECS components provide a neuroprotective effect [89], making the ECS neurobiochemistry a popular target in neurodegenerative disease therapeutics. This has opened up many research threads of attempting to identify the molecular mechanisms, cascade pathways, and genetic and transcription factors involved in ECS in PD and AD.

A study evidenced that the CB1R expression was reduced in PD patients; however, it did not show whether this expression level changes were due to the parkinsonism or the LDOPA treatment of the patients [90]. Furthermore, Parkinson's disease rat models with reserpine treatment commonly used for decelerating the activity of the nervous system showed reduced expression of CB1R in the striatum [69]. The close association of the locomotor symptoms of PD and the ECS neurotransmitters, anandamide and 2-AG, was explained. The levels of dopamine receptor agonists used for motor symptoms significantly reduce the levels of both endocannabinoid neurotransmitters and administration of CBR1 antagonist along with the dopamine receptor agonists, which completely restored the motor symptoms of Parkinson's disease mouse [91]. Modulation of the expression of $A B H D 6$ has been popular in the last few years due to its major role in ECS. Female hormones, oestrogen and progesterone, overexpressed ABHD6 in immune cells leading to development of autoimmune reactions [92]. ABHD6 modulation of 2-AG levels, and the subsequent activation of cannabinoid receptors [93], can be utilised as a target for drug designing in PD and AD models.

\section{Neuroinflammation and the Endocannabinoid System}

The action of inflammation in the onset of $\mathrm{PD}$ and $\mathrm{AD}$ is being evidenced through several studies [4]. As the inflammatory 
modulator in the brain, microglia are known to play an important role in the neuro-inflammation-mediated neurodegeneration. A recent review well describes the three major functions of microglia: constant sensing the environmental change, basic housekeeping to maintain regular neuronal function, and neuroprotective function [94]. The authors further described the microglia as a 'double-edged sword', due to its activity of $A \beta$ uptake and clearance inducing neuroprotection [95], yet the persistent accumulation of $A \beta$ activates microglia resulting in further accumulation of the peptides [94]. However, a transcriptome-sequence analysis identifies this activity to be performed by a unique type of novel microglia known as disease-associated microglia (DAM), which are located near the $\mathrm{A} \beta$ plaques in the $\mathrm{AD}$ brain [96]. It is hypothesised that these microglia act in a similar way in PD brain with Lewy body formation with $\alpha$-synuclein. Even though the exact mechanism is not well understood, it is suggested that microglia activate in early PD brain in order to remove progressively accumulating $\alpha$-synuclein; however, with the progression of the disease, the microglia act as phagocytes damaging the neurons [97].

The relationship between the ECS and NDDs has been studied intensively with regard to the neuroinflammation perspective. However, the effects of ECS on microglia in neuroinflammation are not well established and the associated data are limited. Several recent studies have discussed the association between the endocannabinoid system and the microglial phenotype in neuropathology. The current knowledge suggests that microglia in normal healthy brain maintain the homeostasis with M0-type morphology. The activation and polarisation of microglia due to an injury or related stimulus induce the secretion of pro-inflammatory cytokines for neuroinflammation with classical M1-type morphology. However, with the persistent activation, thus the persistent neuroinflammation leads to neurodegeneration. Alternatively, the microglia induce neuroprotection through alternative M2-type morphology by secreting anti-inflammatory cytokines [98, 99]. Similar to neurons, microglia consist of complete ECS with endocannabinoids synthesised within the cells and the GPCR cannabinoid receptors expressed on the cell membrane. Studies suggest that immune-modulatory CB2R are comparatively more abundant in microglia than $\mathrm{CB} 1 \mathrm{R}$ and significantly upregulate during pathological conditions [100], and binding of either endocannabinoids or phytocannabinoids induces gene expression to shift microglia into less harmful M2 phenotype for neuronal protection. Researchers hypothesise that the cannabinoid agonist-initiated signalling drives the microglia into a more balanced state between M1 and M2 types and also upregulates M0-type morphology gene expression [98]. This supports the idea of therapeutic potential of both endocannabinoids and phytocannabinoids targeting microglia for neuroprotection and possible prevention of neurodegeneration strategies. However, further in-depth transcriptomics studies are necessary to determine the precise molecular mechanism of action for cannabinoids' effect on microglia.

The inhibition of FAAH reduced the dopaminergic neuronal death, simultaneously decreasing immune-reactivity through microglial inhibition leading to improvement in parkinsonismlike motor symptoms [101]. The microglia overexpressed the CB2R and FAAH inducing inflammatory response in the brain leading to $\mathrm{AD}$ and $\mathrm{CB} 2 \mathrm{R}$ deficiency reduced neuroinflammation $[102,103]$. Furthermore, there was an induced expression of $\mathrm{CB} 2 \mathrm{R}$ in activated microglia during neuroinflammation, which was absent in the inactive microglia at rest $[104,105]$. The data can be supported by the study, where they used $\mathrm{CB} 2 \mathrm{R}+/+$ and $\mathrm{CB} 2 \mathrm{R}-/-$ microglia cell cultures to stimulate with pro-/anti-inflammatory stimulus and observed that cells with no CB2R responded weakly to the pro-inflammatory stimuli than microglia expressing CB2R [103]. Similar results were obtained with the APP/S1 AD mouse models with further reduced concentrations of soluble $A \beta$ in the mouse brain with no CB2R expression [103]. These data indicate the importance of the cannabinoid receptor expression for microglia activation and neuroinflammation. This suggests the potential of controlling the cannabinoid receptor expression or receptor stimulation which can be directed to inhibition of the microglia activation, and subsequent neuroinflammation and neurodegeneration. A study supported this theory that stimulation of CB1R and CB2R with receptor agonist WIN-55212-2 reduced the microglial activation [106]. Therefore, further studies shall provide clear understanding of the detailed association of ECS in microglia activation. Currently, no microglia-mediated neuroinflammation-targeted cannabinoid drugs are available or under clinical investigation; thus, it can be suggested as a novel theme in the industry to develop ECS-targeted therapeutics for neurodegeneration.

In contrast to the microglia-mediated neuroinflammation, the association of cytokines in neuroinflammation leading to neurodegeneration is well studied. A study conducted with cultured mouse macrophages concluded that 2-AG inhibits production of IL-6 and increases iNOS-dependent nitric oxide (NO) synthesis, leading to macrophage inhibition; thus, the ECS activation reduces inflammatory response [107]. Since the first discovery of expression level changes in cytokines such as IFN- $\alpha / \beta$ with THC treatment in late 1900 s $[108,109]$, different cannabinoid-based drugs have been developed for a wide scope of diseases from general obesity to different cancers [110]. A study using AD mouse models treated with CBD observed direct impact on $\mathrm{A} \beta$-mediated neuroinflammation [83]. Even though the exact molecular mechanism is unknown, the researchers suggest that the CBD may be responsible for diminishing gliosis which ultimately results in hold in neuroinflammation and neurodegeneration. However, the precise mechanism of inflammatory mediator cytokines related to endocannabinoid system in PD and AD is yet to be understood. 


\section{Endocannabinoid System in Other Diseases}

In addition to PD and $\mathrm{AD}$, the ECS has been intensively studied as high potential target for therapeutics for other disease conditions as well. The involvement of ECS in pain perception and reward processing makes the ECS a target for treatment for chronic pain [111]. The ECS genetics have shown close association with energy and glucose metabolism, thereby affecting the diabetes conditions [112]. The published literature also evidence that the ECS exerts a neuroprotective effect on stroke where CB1R and CB2R antagonists have the potential to be developed into therapeutics for stroke [113]. A summary of collection of published data for other diseases associated with ECS component is given in Table 1.

Table 1 Published literature for the association of ECS and phytocannabinoids as potential drug target for common non-communicable diseases

\begin{tabular}{|c|c|c|c|}
\hline Condition & Endocannabinoid ligand/receptor & Action & Reference \\
\hline \multicolumn{4}{|l|}{ Other neurological disorders } \\
\hline Chronic pain & Anandamide & $\begin{array}{l}\text { Release of anandamide in pain suppressor neural } \\
\text { circuits as a treatment for pain }\end{array}$ & [114] \\
\hline Neuropathic pain & CB1R and CB2R & $\begin{array}{l}\text { Neuronal injury and neuropathic pain reduced CB1R } \\
\text { expression and increased CB2R expression. }\end{array}$ & [115] \\
\hline Huntington's disease & CB1R & $\begin{array}{l}\text { CB1R loss is observed and overexpression exerted } \\
\text { neuroprotection against Huntington. } \\
\text { Therapeutic delay of CB1R loss may delay the } \\
\text { disease progression. }\end{array}$ & {$[116-118]$} \\
\hline Schizophrenia & $\mathrm{CBD}$ and anandamide & $\begin{array}{l}\text { CBD significantly enhanced anandamide levels in } \\
\text { serum, diminishing psychosis. Therapeutics to } \\
\text { retain anandamide in serum could induce } \\
\text { anti-psychotic effects. }\end{array}$ & [119-121] \\
\hline \multirow[t]{2}{*}{ Amyotrophic lateral sclerosis (ALS) } & $\Delta^{9} \mathrm{THC}$ and $\mathrm{CBD} / \mathrm{CB} 2 \mathrm{R}$ & $\begin{array}{l}\text { Exerted neuroprotection through upregulation } \\
\text { of CB2R in } \Delta^{9} \mathrm{THC} \text { and CBD-treated } \\
\text { ALS mouse models. }\end{array}$ & [122] \\
\hline & $\Delta^{9} \mathrm{THC}$ & $\begin{array}{l}\text { Delayed motor impairments and exerted } \\
\text { neuroprotection through reducing oxidative } \\
\text { damage to the spinal cord in THC-treated ALS } \\
\text { mouse models. }\end{array}$ & [123] \\
\hline \multicolumn{4}{|l|}{ Cardiovascular diseases } \\
\hline Stroke & $2-\mathrm{AG}$ & $\begin{array}{l}\text { Administration } 2-A G \text { to rat models significantly re- } \\
\text { duced blood flow to the brain. Authors state } \\
\text { warning in clinical trials. }\end{array}$ & {$[124]$} \\
\hline $\begin{array}{l}\text { Reperfused acute myocardial } \\
\text { infarction (AMI) }\end{array}$ & CBD & $\begin{array}{l}\text { CBD-treated AMI rabbit models showed increased } \\
\text { systolic wall thickness with increased blood flow } \\
\text { and reduced inflammation. }\end{array}$ & {$[125]$} \\
\hline Cardiac ischaemia & CBD & Reduced systolic blood pressure in patients & [126] \\
\hline \multicolumn{4}{|l|}{ Diabetes } \\
\hline \multirow[t]{3}{*}{ Type-II diabetes } & CBD & $\begin{array}{l}\text { CBD treatment in mice significantly reduced } \\
\text { pro-inflammatory cytokines: IFN- } \gamma, \text { TFN- } \alpha \text {. TH1 } \\
\text { cytokines were reduced and TH } 2 \text { cytokines (IL- } 4 \text {, } \\
\text { IL-10) were increased. } \\
\text { Overall diabetes incidences were reduced. }\end{array}$ & {$[127]$} \\
\hline & $\begin{array}{l}\mathrm{CBD} \text { and } \\
\Delta^{9} \text {-tetrahydrocannabivarin }(\mathrm{THCV})\end{array}$ & $\begin{array}{l}\text { Patients administered with CBD reduced resistin } \\
\text { and increased glucose-dependent insulinotropic } \\
\text { peptide levels; components directly associated } \\
\text { with obesity. }\end{array}$ & {$[128]$} \\
\hline & & $\begin{array}{l}\text { THCV administration significantly reduced fasting } \\
\text { blood glucose levels. }\end{array}$ & \\
\hline \multicolumn{4}{|l|}{ Autoimmune disorders } \\
\hline Corneal hyperalgesia & $\Delta^{8} \mathrm{THC} / \mathrm{CB} 1 \mathrm{R}$ & $\begin{array}{l}\text { Stimulation and activation of CB1R with } \\
\Delta^{8} \mathrm{THC} \text { significantly reduced pain } \\
\text { and corneal inflammation }\end{array}$ & [129] \\
\hline Inflammatory skin disorders & CBD & $\begin{array}{l}\text { Patients of psoriasis and atopic dermatitis tropically } \\
\text { administrated with CBD ointment showed } \\
\text { significant improvements in skin condition. }\end{array}$ & {$[130]$} \\
\hline
\end{tabular}




\section{Cannabis sativa and Other Phytocannabinoids}

Apart from these natural cannabinoids in the brain, the CB1R and $\mathrm{CB} 2 \mathrm{R}$ act as receptors for several external cannabinoids ligands. The plant Cannabis sativa (commonly known as marijuana) contains over 60 different pharmacologically active cannabinoids (phytocannabinoids) $[88,131]$ identified to date, out of which are $\Delta^{9} \mathrm{THC}$, the major psychoactive compound of the plant [132], and CBD, the non-psychoactive compound of the plant [72] which are being studied widely for their neuroprotective characteristics. The phytocannabinoids for PD and AD are being used in cell culture models [75, 82], animal models [73, 133], and in clinical trials [134] in published data, as were described above. Alternatively to $C$. sativa, several other plant species have been identified for cannabinoid-like natural compounds (also known as cannabimimetics), which exert similar physiological activities. The alkylamides from Echinacea species (cornflower), such as E. purpurea and E. angustifolia, are structurally closely similar to the endocannabinoids allowing them to bind with cannabinoid receptors $[135,136]$. The cannabimimetics have also been identified in Theobroma cacao (chocolate), Heliopsis helianthoides (oxeye), Helichrysum umbraculigerum (sunflower), Acmella oleracea (electric daisy), Radula marginata (liverwort), and Piper nigrum (black pepper) plants [137], making the CB receptor ligands naturally abundant for therapeutics.

\section{Limitations and Benefits of Cannabinoid-Based Drugs}

Clinical trials and cohort studies using Cannabis plant extracts or direct administration of dried plant leaves have shown severe adverse effects on $\mathrm{PD}$ and $\mathrm{AD}$ patients, including fatal effects due to the toxicity exerted in the neurodegenerated brain [134], which raises a controversial argument of using the compounds as clinical therapeutics. This has directed researchers to study ECS and its natural components, cannabinoid receptors and ligands (anandamides and 2-AG), at the molecular and biochemical levels in order to understand its effects on neurodegenerated brain and overall on the central nervous system $[48,138]$.

With the understanding of the demand for further research, new techniques are being developed. A recent such technique identifies the endocannabinoids in the blood plasma through ultra-high-performance liquid chromatography-tandem mass spectrometry (UHPLC-MS/MS) [139]. Molecular docking studies for cannabinoid-based drug designing have been conducted with several bioinformatics tools [140]. These include different lead molecules, cannabinoids, and cannabimimetics [141] targeting CB1R [142] and CB2R [143, 144]. However, no successfully completed PD- or AD-targeted cannabinoidbased drug designing studies were found in the literature. This identifies the research gap of identifying potential gene targets in endocannabinoid system and to develop potential candidate leads focused on PD and $\mathrm{AD}$ conditions.

With the aforementioned data discussed, it must also highlight that the cannabinoid-based therapeutic drugs may have their own pros and cons. With cultural beliefs of the developing world and different perspectives, there can be a hesitation in acceptance of cannabinoids for treatment purpose. On the other hand, the administration of cannabinoid drugs must be highly regulated to avoid adverse effects of potential overdosing as well as the treatments should be well monitored by a health professional, to avoid development of addiction to the drugs. On the contrary, the ECS is a novel system still under investigation that may have a wide network associated with other primary systems of the human body. Therefore, there may be potential therapeutic benefit for wide range of non-communicable diseases. The knowledge of genetics of ECS is not well established, where the application advanced technologies such as GWAS and epigenetics, and there may lie answers to many key questions in drug development not only for NDDs but also for other disease conditions.

\section{Conclusion}

Both PD and AD are known to have multifactor aetiology, yet the precise involvement of genetic, environmental, and behavioural factors is to be elucidated. It is well evidenced that research studies thus far have mainly focused on clinical and epidemiological cohort studies rather than on molecular-based investigations. Therefore, molecular approaches show a high demand and significance to determine the genetics and other aspects of endocannabinoid system involved in the onset of PD and AD for development of therapeutics drugs targeting preventing, ceasing, and repairing neurodegeneration.

Acknowledgments The senior personnel Prof. Shiroma Handunnetti of Institute of Biochemistry, Molecular biology \& Biotechnology, University of Colombo, Sri Lanka, and Prof. Athula Sumathipala of Keele University, UK, and Institute for Research \& Development, Colombo, Sri Lanka, are kindly acknowledged.

\section{Compliance with Ethical Standards}

Conflicts of Interest The authors declare that they have no conflict of interest.

Ethics Approval Not applicable.

Consent to Participate Not applicable.

Consent for Publication All authors provide consent for publication. 
Open Access This article is licensed under a Creative Commons Attribution 4.0 International License, which permits use, sharing, adaptation, distribution and reproduction in any medium or format, as long as you give appropriate credit to the original author(s) and the source, provide a link to the Creative Commons licence, and indicate if changes were made. The images or other third party material in this article are included in the article's Creative Commons licence, unless indicated otherwise in a credit line to the material. If material is not included in the article's Creative Commons licence and your intended use is not permitted by statutory regulation or exceeds the permitted use, you will need to obtain permission directly from the copyright holder. To view a copy of this licence, visit http://creativecommons.org/licenses/by/4.0/.

\section{References}

1. WHO (2018) Global burden of neurological disorders: estimates and projections neurological disorders: public health challenges, Geneva

2. Hirsch L, Jette N, Frolkis A, Steeves T, Pringsheim T (2016) The incidence of Parkinson's disease: a systematic review and metaanalysis. Neuroepidemiology 46(4):292-300

3. Galvan A, Wichmann T (2008) Pathophysiology of Parkinsonism. Clin Neurophysiol 119(7):1459-1474. https://doi.org/10.1016/j. clinph.2008.03.017

4. Skaper SD, Facci L, Zusso M, Giusti P (2018) An inflammationcentric view of neurological disease: beyond the neuron. Front Cell Neurosci 12:72

5. Polymeropoulos MH, Lavedan C, Leroy E, Ide SE, Dehejia A, Dutra A, Pike B, Root H et al (1997) Mutation in the $\alpha$-synuclein gene identified in families with Parkinson's disease. Science 276(5321):2045-2047

6. Polymeropoulos MH, Lavedan C, Leroy E, Ide SE, Dehejia A, Dutra A, Pike B, Root H et al (1997) Mutation in the alphasynuclein gene identified in families with Parkinson's disease. Science 276(5321):2045-2047

7. Kumazawa R, Tomiyama H, Li Y, Imamichi Y, Funayama M, Yoshino H, Yokochi F, Fukusako T et al (2008) Mutation analysis of the PINK1 gene in 391 patients with Parkinson disease. Arch Neurol 65(6):802-808. https://doi.org/10.1001/archneur.65.6.802

8. Paisán-Ruíz C, Jain S, Evans EW, Gilks WP, Simón J, Van Der Brug M, De Munain AL, Aparicio S et al (2004) Cloning of the gene containing mutations that cause PARK8-linked Parkinson's disease. Neuron 44(4):595-600

9. Abou-Sleiman PM, Healy DG, Quinn N, Lees AJ, Wood NW (2003) The role of pathogenic DJ-1 mutations in Parkinson's disease. Ann Neurol 54(3):283-286. https://doi.org/10.1002/ana. 10675

10. Nussbaum RL, Ellis CE (2003) Alzheimer's disease and Parkinson's disease. N Engl J Med 348(14):1356-1364

11. Nalls MA, Pankratz N, Lill CM, Do CB, Hernandez DG, Saad M, DeStefano AL, Kara E et al (2014) Large-scale meta-analysis of genome-wide association data identifies six new risk loci for Parkinson's disease. Nat Genet 46(9):989-993. https://doi.org/ 10.1038/ng.3043

12. Aharon-Peretz J, Rosenbaum H, Gershoni-Baruch R (2004) Mutations in the glucocerebrosidase gene and Parkinson's disease in Ashkenazi Jews. N Engl J Med 351(19):1972-1977

13. Polymeropoulos MH (2000) Genetics of Parkinson's disease. Ann N Y Acad Sci 920:28-32

14. Milosevic J, Schwarz SC, Ogunlade V, Meyer AK, Storch A, Schwarz J (2009) Emerging role of LRRK2 in human neural progenitor cell cycle progression, survival and differentiation. Mol Neurodegener 4:25. https://doi.org/10.1186/1750-1326-4-25

15. Kay L, Pienaar IS, Cooray R, Black G, Soundararajan M (2018) Understanding miro GTPases: implications in the treatment of neurodegenerative disorders. Mol Neurobiol 55(9):7352-7365. https://doi.org/10.1007/s12035-018-0927-x

16. LeMoyne R, Mastroianni T, Whiting D, Tomycz N (2019) New perspectives for network centric therapy for the treatment of Parkinson's disease and essential tremor. In: Wearable and Wireless Systems for Healthcare II. Smart Sensors, Measurement and Instrumentation (SSMI), vol 31. Springer, Singapore, pp. 127 128. https://doi.org/10.1007/978-981-13-5808-1_10

17. Bourque M, Morissette M, Di Paolo T (2019) Repurposing sex steroids and related drugs as potential treatment for Parkinson's disease. Neuropharmacology 147:37-54

18. Sawamoto N, Takahashi R (2018) Kyoto trial to evaluate the safety and efficacy of iPSC-derived dopaminergic progenitors in the treatment of Parkinson's disease. UMIN-CTR Clinical Trial. https://upload.umin.ac.jp/cgi-open-bin/ctr_e/ctr_view.cgi? recptno=R000038278.

19. Wang S, Zou C, Fu L, Wang B, An J, Song G, Wu J, Tang X et al (2015) Autologous iPSC-derived dopamine neuron transplantation in a nonhuman primate Parkinson's disease model. Cell Discov 1(1):1-11

20. Kirkeby A, Parmar M, Barker RA (2017) Strategies for bringing stem cell-derived dopamine neurons to the clinic: A European approach (STEM-PD). Prog Brain Res 230:165-190. https://doi. org/10.1016/bs.pbr.2016.11.011

21. Selkoe DJ (2011) Alzheimer's disease. Cold Spring Harb Perspect Biol 3(7). https://doi.org/10.1101/cshperspect.a004457

22. Imbimbo BP, Lombard J, Pomara N (2005) Pathophysiology of Alzheimer's disease. Neuroimaging Clin 15(4):727-753

23. Kumar A, Singh A, Ekavali (2015) A review on Alzheimer's disease pathophysiology and its management: an update. Pharmacol Rep 67(2):195-203. https://doi.org/10.1016/j.pharep. 2014.09.004

24. van de Weijer MP, Jansen IE, Verboven AH, Andreassen OA, Posthuma D (2020) Genomics of Alzheimer's disease. Pers Psychiatry Elsevier:275-283. https://doi.org/10.1016/B978-0-12813176-3.00022-5

25. Shi Y, Liu H, Yang C, Xu K, Cai Y, Wang Z, Zhao Z, Shao T et al (2020) Transcriptomic analyses for identification and prioritization of genes associated with Alzheimer's disease in humans. Front Bioeng Biotechnol 8(31). https://doi.org/10.3389/fbioe. 2020.00031

26. Wilkins JM, Trushina E (2018) Application of metabolomics in Alzheimer's disease. Front Neurol 8:719

27. Salter MW, Stevens B (2017) Microglia emerge as central players in brain disease. Nat Med 23(9):1018-1027. https://doi.org/10. 1038/nm.4397

28. Zheng H, Cheng B, Li Y, Li X, Chen X, Zhang Y-W (2018) TREM2 in Alzheimer's disease: microglial survival and energy metabolism. Front Aging Neurosci 10. https://doi.org/10.3389/ fnagi.2018.00395

29. Ulrich JD, Finn M, Wang Y, Shen A, Mahan TE, Jiang H, Stewart FR, Piccio L et al (2014) Altered microglial response to $A \beta$ plaques in APPPS1-21 mice heterozygous for TREM2. Mol Neurodegener 9(1):20. https://doi.org/10.1186/1750-1326-9-20

30. Zheng H, Jia L, Liu C-C, Rong Z, Zhong L, Yang L, Chen X-F, Fryer JD et al (2017) TREM2 promotes microglial survival by activating Wnt/ $\beta$-catenin pathway. J Neurosci 37(7):1772-1784. https://doi.org/10.1523/jneurosci.2459-16.2017

31. Wang Y, Cella M, Mallinson K, Jason K, Michelle GS, Gokul SS, Bernd D, John CM (2015) TREM2 lipid sensing sustains the microglial response in an Alzheimer's disease model. Cell 160(6):1061-1071. https://doi.org/10.1016/j.cell.2015.01.049 
32. Ulland TK, Song WM, Huang SC-C, Ulrich JD, Sergushichev A, Beatty WL, Loboda AA, Zhou Y et al (2017) TREM2 maintains microglial metabolic fitness in Alzheimer's disease. Cell 170(4): 649-663.e613. https://doi.org/10.1016/j.cell.2017.07.023

33. Efthymiou AG, Goate AM (2017) Late onset Alzheimer's disease genetics implicates microglial pathways in disease risk. Mol Neurodegener 12(1). https://doi.org/10.1186/s13024-017-0184-x

34. Saxena M, Dubey R (2019) Target enzyme in Alzheimer's disease: acetylcholinesterase inhibitors. Curr Top Med Chem

35. Wang Y, Yang Y, Hong KH, Ning Y, Yu P, Ren J, Ji M, Cai J (2019) Design, synthesis and evaluation of a novel metal chelator as multifunctional agents for the treatment of Alzheimer's disease. Bioorg Chem 87:720-727. https://doi.org/10.1016/j.bioorg.2019. 03.064

36. Frölich L, Atri A, Ballard C, Tariot PN, Molinuevo JL, Boneva N, Geist MA, Raket LL et al (2019) Open-label, multicenter, phase III extension study of idalopirdine as adjunctive to donepezil for the treatment of mild-moderate Alzheimer's disease. J Alzheimers Dis 67(1):303-313

37. Olivares D, Deshpande VK, Shi Y, Lahiri DK, Greig NH, Rogers JT, Huang X (2012) N-methyl D-aspartate (NMDA) receptor antagonists and memantine treatment for Alzheimer's disease, vascular dementia and Parkinson's disease. Curr Alzheimer Res 9(6): 746-758

38. Ozben T, Ozben S (2019) Neuro-inflammation and antiinflammatory treatment options for Alzheimer's disease. Clin Biochem. https://doi.org/10.1016/j.clinbiochem.2019.04.001

39. Teter B, Morihara T, Lim GP, Chu T, Jones MR, Zuo X, Paul RM, Frautschy SA et al (2019) Curcumin restores innate immune Alzheimer's disease risk gene expression to ameliorate Alzheimer pathogenesis. Neurobiol Dis 127:432-448. https:// doi.org/10.1016/j.nbd.2019.02.015

40. Smilth JS, Janice; Kerchner, Geoff (2017) High dose treatments for Alzheimer's disease. United States Patent,

41. Elkashef A, Vocci F, Huestis M, Haney M, Budney A, Gruber A, el-Guebaly N (2008) Marijuana neurobiology and treatment. Subst Abus 29(3):17-29. https://doi.org/10.1080/ 08897070802218166

42. Augustin SM, Lovinger DM (2018) Functional relevance of endocannabinoid-dependent synaptic plasticity in the central nervous system. ACS Chem Neurosci

43. Devane WA, Hanus L, Breuer A, Pertwee RG, Stevenson LA, Griffin G, Gibson D, Mandelbaum A et al (1992) Isolation and structure of a brain constituent that binds to the cannabinoid receptor. Science 258(5090):1946-1949

44. Mechoulam R, Ben-Shabat S, Hanus L, Ligumsky M, Kaminski NE, Schatz AR, Gopher A, Almog S et al (1995) Identification of an endogenous 2-monoglyceride, present in canine gut, that binds to cannabinoid receptors. Biochem Pharmacol 50(1):83-90

45. Sugiura T, Kondo S, Sukagawa A, Nakane S, Shinoda A, Itoh K, Yamashita A, Waku K (1995) 2-Arachidonoylglycerol: a possible endogenous cannabinoid receptor ligand in brain. Biochem Biophys Res Commun 215(1):89-97

46. Schmid PC, Reddy PV, Natarajan V, Schmid HH (1983) Metabolism of $\mathrm{N}$-acylethanolamine phospholipids by a mammalian phosphodiesterase of the phospholipase D type. J Biol Chem 258(15):9302-9306

47. Ahn K, McKinney MK, Cravatt BF (2008) Enzymatic pathways that regulate endocannabinoid signaling in the nervous system. Chem Rev 108(5):1687-1707. https://doi.org/10.1021/cr0782067

48. Zou S, Kumar U (2018) Cannabinoid receptors and the endocannabinoid system: signaling and function in the central nervous system. Int J Mol Sci 19(3):833. https://doi.org/10. 3390/ijms19030833
49. McKinney MK, Cravatt BF (2005) Structure and function of fatty acid amide hydrolase. Annu Rev Biochem 74:411-432. https:// doi.org/10.1146/annurev.biochem.74.082803.133450

50. Goparaju SK, Ueda N, Yamaguchi H, Yamamoto S (1998) Anandamide amidohydrolase reacting with 2arachidonoylglycerol, another cannabinoid receptor ligand. FEBS Lett 422(1):69-73

51. Kind L, Kursula P (2019) Structural properties and role of the endocannabinoid lipases ABHD6 and ABHD12 in lipid signalling and disease. Amino Acids 51(2):151-174

52. Dinh TP, Freund TF, Piomelli D (2002) A role for monoglyceride lipase in 2-arachidonoylglycerol inactivation. Chem Phys Lipids 121(1-2):149-158

53. Bisogno T, Di Marzo V (2010) Cannabinoid receptors and endocannabinoids: role in neuroinflammatory and neurodegenerative disorders. CNS Neurol Disord Drug Targets 9(5):564-573

54. Zhang J, Chen C (2008) Endocannabinoid 2-arachidonoylglycerol protects neurons by limiting COX-2 elevation. J Biol Chem 283(33):22601-22611

55. McPartland JM, Glass M (2003) Functional mapping of cannabinoid receptor homologs in mammals, other vertebrates, and invertebrates. Gene 312:297-303

56. Galiegue S, Mary S, Marchand J, Dussossoy D, Carriere D, Carayon P, Bouaboula M, Shire D et al (1995) Expression of central and peripheral cannabinoid receptors in human immune tissues and leukocyte subpopulations. Eur J Biochem 232(1):54 61

57. Matias I, Pochard P, Orlando P, Salzet M, Pestel J, Di Marzo V (2002) Presence and regulation of the endocannabinoid system in human dendritic cells. Eur J Biochem 269(15):3771-3778

58. Lauckner JE, Jensen JB, Chen H-Y, Lu H-C, Hille B, Mackie K (2008) GPR55 is a cannabinoid receptor that increases intracellular calcium and inhibits M current. Proc Natl Acad Sci U S A 105(7):2699-2704. https://doi.org/10.1073/pnas.0711278105

59. Piomelli D (2003) The molecular logic of endocannabinoid signalling. Nat Rev Neurosci 4(11):873

60. Gyombolai P, Pap D, Turu G, Catt KJ, Bagdy G, Hunyady L (2012) Regulation of endocannabinoid release by $G$ proteins: a paracrine mechanism of $\mathrm{G}$ protein-coupled receptor action. Mol Cell Endocrinol 353(1-2):29-36

61. Navarrete M, Araque A (2008) Endocannabinoids mediate neuron-astrocyte communication. Neuron 57(6):883-893

62. Fernández-Ruiz J, Romero J, Ramos JA (2015) Endocannabinoids and neurodegenerative disorders: Parkinson's disease, Huntington's chorea, Alzheimer's disease, and others. In: Pertwee R (ed) Endocannabinoids. Handb Exp Pharmacol, 231(2015). Springer, pp. 233-259. https://doi.org/10.1007/978-3-319-20825-1 8

63. Talarico G, Trebbastoni A, Bruno G, de Lena C (2019) Modulation of the cannabinoid system: a new perspective for the treatment of the Alzheimer's disease. Curr Neuropharmacol 17(2):176-183

64. Martínez-Pinilla E, Aguinaga D, Navarro G, Rico AJ, Oyarzábal J, Sánchez-Arias JA, Lanciego JL, Franco R (2019) Targeting CB 1 and GPR55 endocannabinoid receptors as a potential neuroprotective approach for Parkinson's disease. Mol Neurobiol 56(8):5900 5910. https://doi.org/10.1007/s12035-019-1495-4

65. Mnich K, Finn DP, Dowd E, Gorman AM (2010) Inhibition by anandamide of 6-hydroxydopamine-induced cell death in PC12 cells. Int J Cell Biol 2010(2010):818497. https://doi.org/10.1155/ 2010/818497

66. Mounsey RB, Mustafa S, Robinson L, Ross RA, Riedel G, Pertwee RG, Teismann P (2015) Increasing levels of the endocannabinoid 2-AG is neuroprotective in the 1-methyl-4-phenyl-1,2,3,6-tetrahydropyridine mouse model of Parkinson's disease. Exp Neurol 273:36-44. https://doi.org/10.1016/j. expneurol.2015.07.024 
67. Milton NGN (2002) Anandamide and noladin ether prevent neurotoxicity of the human amyloid- $\beta$ peptide. Neurosci Lett 332(2): 127-130. https://doi.org/10.1016/S0304-3940(02)00936-9

68. Cerri S, Levandis G, Ambrosi G, Montepeloso E, Antoninetti GF, Franco R, Lanciego JL, Baqi Y et al (2014) Neuroprotective potential of adenosine A2A and cannabinoid CB1 receptor antagonists in an animal model of Parkinson disease. J Neuropathol Exp Neurol 73(5):414-424. https://doi.org/10.1097/nen. 0000000000000064

69. Silverdale MA, McGuire S, McInnes A, Crossman AR, Brotchie JM (2001) Striatal Cannabinoid CB1 receptor mRNA expression is decreased in the reserpine-treated rat model of Parkinson's disease. Exp Neurol 169(2):400-406. https://doi.org/10.1006/exnr. 2001.7649

70. Bedse G, Romano A, Cianci S, Lavecchia AM, Lorenzo P, Elphick MR, LaFerla FM, Vendemiale G et al (2014) Altered expression of the CB1 cannabinoid receptor in the triple transgenic mouse model of Alzheimer's disease. J Alzheimers Dis 40(3): 701-712

71. Haghani M, Shabani M, Javan M, Motamedi F, Janahmadi M (2012) CB1 cannabinoid receptor activation rescues amyloid $\beta$ induced alterations in behaviour and intrinsic electrophysiological properties of rat hippocampal CA1 pyramidal neurones. Cell Physiol Biochem 29(3-4):391-406

72. Zuardi AW, Crippa JAS, Hallak JEC, Moreira FA, Guimarães FS (2006) Cannabidiol, a Cannabis sativa constituent, as an antipsychotic drug. Braz J Med Biol Res 39:421-429

73. van Vliet SA, Vanwersch RA, Jongsma MJ, Olivier B, Philippens IH (2008) Therapeutic effects of $\Delta 9$-THC and modafinil in a marmoset Parkinson model. Eur Neuropsychopharmacol 18(5): 383-389

74. Moss D, McMaster S, Rogers J (1981) Tetrahydrocannabinol potentiates reserpine-induced hypokinesia. Pharmacol Biochem Behav 15(5):779-783

75. Carroll C, Zeissler ML, Hanemann C, Zajicek J (2012) $\Delta$ 9-tetrahydrocannabinol $(\triangle 9-\mathrm{THC})$ exerts a direct neuroprotective effect in a human cell culture model of Parkinson's disease. Neuropathol Appl Neurobiol 38(6):535-547

76. Lastres-Becker I, Cebeira M, De Ceballos M, Zeng BY, Jenner P, Ramos JA, Fernandez-Ruiz J (2001) Increased cannabinoid CB1 receptor binding and activation of GTP-binding proteins in the basal ganglia of patients with Parkinson's syndrome and of MPTP-treated marmosets. Eur J Neurosci 14(11):1827-1832

77. Fagherazzi EV, Garcia VA, Maurmann N, Bervanger T, Halmenschlager LH, Busato SB, Hallak JE, Zuardi AW et al (2012) Memory-rescuing effects of cannabidiol in an animal model of cognitive impairment relevant to neurodegenerative disorders. Psychopharmacology 219(4):1133-1140

78. Zuardi AW, Crippa J, Hallak JEC, Pinto J, Chagas MHN, Rodrigues G, Dursun S, Tumas V (2009) Cannabidiol for the treatment of psychosis in Parkinson's disease. J Psychopharmacol 23(8):979-983

79. Chagas MHN, Zuardi AW, Tumas V, Pena-Pereira MA, Sobreira ET, Bergamaschi MM, dos Santos AC, Teixeira AL et al (2014) Effects of cannabidiol in the treatment of patients with Parkinson's disease: an exploratory double-blind trial. J Psychopharmacol 28(11):1088-1098

80. Santos NAG, Martins NM, Sisti FM, Fernandes LS, Ferreira RS, Queiroz RHC, Santos AC (2015) The neuroprotection of cannabidiol against MPP+-induced toxicity in PC12 cells involves trkA receptors, upregulation of axonal and synaptic proteins, neuritogenesis, and might be relevant to Parkinson's disease. Toxicol In Vitro 30(1, Part B):231-240. https://doi.org/10.1016/ j.tiv.2015.11.004

81. Franke TN, Irwin C, Beindorff N, Bouter Y, Bouter C (2019) Effects of tetrahydrocannabinol treatment on brain metabolism and neuron loss in a mouse model of sporadic Alzheimer's disease. Nuklearmedizin 58(02):P94. https://doi.org/10.1055/s-00391683689

82. Cao C, Li Y, Liu H, Bai G, Mayl J, Lin X, Sutherland K, Nabar N et al (2014) The potential therapeutic effects of THC on Alzheimer's disease. J Alzheimers Dis 42(3):973-984

83. Esposito G, Scuderi C, Savani C, Steardo L Jr, De Filippis D, Cottone P, Iuvone T, Cuomo V et al (2007) Cannabidiol in vivo blunts $\beta$-amyloid induced neuroinflammation by suppressing IL$1 \beta$ and iNOS expression. Br J Pharmacol 151(8):1272-1279. https://doi.org/10.1038/sj.bjp.0707337

84. Cheng D, Spiro AS, Jenner AM, Garner B, Karl T (2014) Longterm cannabidiol treatment prevents the development of social recognition memory deficits in Alzheimer's disease transgenic mice. J Alzheimers Dis 42(4):1383-1396

85. Aso E, Andres-Benito P, Carmona M, Maldonado R, Ferrer I (2016) Cannabinoid receptor 2 participates in amyloid-beta processing in a mouse model of Alzheimer's disease but plays a minor role in the therapeutic properties of a cannabis-based medicine. Journal of Alzheimers Dis : JAD 51(2):489-500. https://doi. org/10.3233/jad-150913

86. Watt G, Karl T (2017) In vivo evidence for therapeutic properties of cannabidiol (CBD) for Alzheimer's disease. Front Pharmacol 8(20). https://doi.org/10.3389/fphar.2017.00020

87. van Amsterdam J, Brunt T, van den Brink W (2015) The adverse health effects of synthetic cannabinoids with emphasis on psychosis-like effects. J Psychopharmacol 29(3):254-263

88. Andre CM, Hausman J-F, Guerriero G (2016) Cannabis sativa: the plant of the thousand and one molecules. Front Plant Sci 7(19). https://doi.org/10.3389/fpls.2016.00019

89. Guzmán M, Sánchez C, Galve-Roperh I (2002) Cannabinoids and cell fate. Pharmacol Ther 95(2):175-184

90. Hurley M, Mash DC, Jenner P (2003) Expression of cannabinoid CB1 receptor mRNA in basal ganglia of normal and parkinsonian human brain. J Neural Transm 110(11):1279-1288

91. Di Marzo V, Hill MP, Bisogno T, Crossman AR, Brotchie JM (2000) Enhanced levels of endogenous cannabinoids in the globus pallidus are associated with a reduction in movement in an animal model of Parkinson's disease. FASEB J 14(10):1432-1438. https://doi.org/10.1096/fasebj.14.10.1432

92. Drehmer MN, Muniz YCN, Marrero AR, Löfgren SE (2019) Gene expression of ABHD6, a key factor in the endocannabinoid system, can be modulated by female hormones in human immune cells. Biochem Genet 57(1):35-45

93. Cao JK, Kaplan J, Stella N (2019) ABHD6: Its place in endocannabinoid signaling and beyond. Trends Pharmacol Sci 40(4):267-277. https://doi.org/10.1016/j.tips.2019.02.002

94. Hickman S, Izzy S, Sen P, Morsett L, El Khoury J (2018) Microglia in neurodegeneration. Nat Neurosci 21(10):13591369. https://doi.org/10.1038/s41593-018-0242-x

95. Yeh FL, Wang Y, Tom I, Gonzalez LC, Sheng M (2016) TREM2 binds to apolipoproteins, including APOE and CLU/APOJ, and thereby facilitates uptake of amyloid-beta by microglia. Neuron 91(2):328-340. https://doi.org/10.1016/j.neuron.2016.06.015

96. Keren-Shaul H, Spinrad A, Weiner A, Matcovitch-Natan O, DvirSzternfeld R, Ulland TK, David E, Baruch K et al (2017) A unique microglia type associated with restricting development of Alzheimer's disease. Cell 169(7):1276-1290.e1217. https://doi. org/10.1016/j.cell.2017.05.018

97. Halliday GM, Stevens CH (2011) Glia: Initiators and progressors of pathology in Parkinson's disease. Mov Disord 26(1):6-17. https://doi.org/10.1002/mds.23455

98. Tanaka M, Sackett S, Zhang Y (2020) Endocannabinoid modulation of microglial phenotypes in neuropathology. Front Neurol 11. https://doi.org/10.3389/fneur.2020.00087 
99. Kelly R, Joers V, Tansey MG, McKernan DP, Dowd E (2020) Microglial phenotypes and their relationship to the cannabinoid system: therapeutic implications for Parkinson's disease. Molecules 25(3):453. https://doi.org/10.3390/ molecules 25030453

100. Maresz K, Carrier EJ, Ponomarev ED, Hillard CJ, Dittel BN (2005) Modulation of the cannabinoid CB2 receptor in microglial cells in response to inflammatory stimuli. J Neurochem 95(2): 437-445. https://doi.org/10.1111/j.1471-4159.2005.03380.x

101. Viveros-Paredes J, Gonzalez-Castañeda R, Escalante-Castañeda A, Tejeda-Martínez A, Castañeda-Achutiguí F, Flores-Soto M (2019) Effect of inhibition of fatty acid amide hydrolase on MPTP-induced dopaminergic neuronal damage. Neurología (English Edition) 34(3):143-152

102. Benito C, Núñez E, Tolón RM, Carrier EJ, Rábano A, Hillard CJ, Romero J (2003) Cannabinoid CB2 receptors and fatty acid amide hydrolase are selectively overexpressed in neuritic plaqueassociated glia in Alzheimer's disease brains. J Neurosci 23(35): 11136-11141

103. Schmöle A-C, Lundt R, Ternes S, Albayram Ö, Ulas T, Schultze JL, Bano D, Nicotera P et al (2015) Cannabinoid receptor 2 deficiency results in reduced neuroinflammation in an Alzheimer's disease mouse model. Neurobiol Aging 36(2):710-719

104. Núñez E, Benito C, Tolón RM, Hillard CJ, Griffin WST, Romero J (2008) Glial expression of cannabinoid CB2 receptors and fatty acid amide hydrolase are beta amyloid-linked events in Down's syndrome. Neuroscience 151(1):104-110. https://doi.org/10. 1016/j.neuroscience.2007.10.029

105. Cassano T, Calcagnini S, Pace L, De Marco F, Romano A, Gaetani S (2017) Cannabinoid receptor 2 signaling in neurodegenerative disorders: from pathogenesis to a promising therapeutic target. Front Neurosci 11(30). https://doi.org/10.3389/fnins. 2017.00030

106. Marchalant Y, Cerbai F, Brothers HM, Wenk GL (2008) Cannabinoid receptor stimulation is anti-inflammatory and improves memory in old rats. Neurobiol Aging 29(12):1894-1901. https://doi.org/10.1016/j.neurobiolaging.2007.04.028

107. Chang YH, Lee ST, Lin WW (2001) Effects of cannabinoids on LPS-stimulated inflammatory mediator release from macrophages: involvement of eicosanoids. J Cell Biochem 81(4):715723

108. Blanchard DK, Newton C, Klein TW, Stewart WE II, Friedman H (1986) In vitro and in vivo suppressive effects of delta-9tetrahydrocannabinol on interferon production by murine spleen cells. Int J Immunopharmacol 8(7):819-824

109. Cabral G, Lockmuller J, Mishkin E (1986) $\Delta$ 9-tetrahydrocannabinol decreases alpha/beta interferon response to herpes simplex virus type 2 in the B6C3F1 mouse. Proc Soc Exp Biol Med 181(2):305-311

110. Klein TW (2005) Cannabinoid-based drugs as anti-inflammatory therapeutics. Nat Rev Immunol 5(5):400

111. Mlost J, Wasik A, Starowicz K (2019) Role of endocannabinoid system in dopamine signalling within the reward circuits affected by chronic pain. Pharmacol Res 143(2019):40-47. https://doi.org/ 10.1016/j.phrs.2019.02.029

112. Doris JM, Millar SA, Idris I, O'Sullivan SE (2019) Genetic polymorphisms of the endocannabinoid system in obesity and diabetes. Diabetes Obes Metab 21(2):382-387. https://doi.org/10.1111/ dom. 13504

113. Kolb B, Saber H, Fadel H, Rajah G (2019) The endocannabinoid system and stroke: a focused review. Brain Circ 5(1):1

114. Walker JM, Huang SM, Strangman NM, Tsou K, Sañudo-Peña MC (1999) Pain modulation by release of the endogenous cannabinoid anandamide. Proc Natl Acad Sci 96(21):12198-12203

115. Luo Y, Zhang J, Chen L, Chen S-R, Chen H, Zhang G, Pan H-L (2020) Histone methyltransferase G9a diminishes expression of cannabinoid CB1 receptors in primary sensory neurons in neuropathic pain. J Biol Chem 295(11):3553-3562

116. Glass M, Van Dellen A, Blakemore C, Hannan A, Faull R (2004) Delayed onset of Huntington's disease in mice in an enriched environment correlates with delayed loss of cannabinoid CB1 receptors. Neuroscience 123(1):207-212

117. Van Laere K, Casteels C, Dhollander I, Goffin K, Grachev I, Bormans G, Vandenberghe W (2010) Widespread decrease of type 1 cannabinoid receptor availability in Huntington disease in vivo. J Nucl Med 51(9):1413-1417

118. Blázquez C, Chiarlone A, Sagredo O, Aguado T, Pazos MR, Resel E, Palazuelos J, Julien B et al (2011) Loss of striatal type 1 cannabinoid receptors is a key pathogenic factor in Huntington's disease. Brain 134(1):119-136

119. Leweke F, Piomelli D, Pahlisch F, Muhl D, Gerth C, Hoyer C, Klosterkötter J, Hellmich M et al (2012) Cannabidiol enhances anandamide signaling and alleviates psychotic symptoms of schizophrenia. Transl Psychiatry 2(3):e94-e94

120. McGuire P, Robson P, Cubala WJ, Vasile D, Morrison PD, Barron R, Taylor A, Wright S (2018) Cannabidiol (CBD) as an adjunctive therapy in schizophrenia: a multicenter randomized controlled trial. Am J Psychiatr 175(3):225-231

121. Gururajan A, Taylor DA, Malone DT (2011) Effect of cannabidiol in a MK-801-rodent model of aspects of Schizophrenia. Behav Brain Res 222(2):299-308. https://doi.org/10.1016/j.bbr.2011. 03.053

122. Moreno-Martet M, Espejo-Porras F, Fernández-Ruiz J, de Lago E (2014) Changes in endocannabinoid receptors and enzymes in the spinal cord of SOD 1G93A transgenic mice and evaluation of a Sativex®-like combination of phytocannabinoids: interest for future therapies in amyotrophic lateral sclerosis. CNS NeurosciTher 20(9):809-815

123. Raman C, McAllister SD, Rizvi G, Patel SG, Moore DH, Abood ME (2004) Amyotrophic lateral sclerosis: delayed disease progression in mice by treatment with a cannabinoid. Amyotroph Lateral Scler Other Motor Neuron Disord 5(1):33-39

124. Shearer JA, Coker SJ, Carswell HVO (2018) Detrimental effects of 2-arachidonoylglycerol on whole blood platelet aggregation and on cerebral blood flow after a focal ischemic insult in rats. Am J Phys Heart Circ Phys 314(5):H967-h977. https://doi.org/10. 1152/ajpheart.00299.2017

125. Feng Y, Chen F, Yin T, Xia Q, Liu Y, Huang G, Zhang J, Oyen R et al (2015) Pharmacologic effects of cannabidiol on acute reperfused myocardial infarction in rabbits: evaluated with $3.0 \mathrm{~T}$ cardiac magnetic resonance imaging and histopathology. J Cardiovasc Pharmacol 66(4):354-363

126. Jadoon KA, Tan GD, O'Sullivan SE (2017) A single dose of cannabidiol reduces blood pressure in healthy volunteers in a randomized crossover study. JCI Insight 2(12). https://doi.org/10. 1172/jci.insight. 93760

127. Weiss L, Zeira M, Reich S, Har-Noy M, Mechoulam R, Slavin S, Gallily R (2006) Cannabidiol lowers incidence of diabetes in nonobese diabetic mice. Autoimmunity 39(2):143-151. https://doi. org/10.1080/08916930500356674

128. Jadoon KA, Ratcliffe SH, Barrett DA, Thomas EL, Stott C, Bell JD, O'Sullivan SE, Tan GD (2016) Efficacy and safety of cannabidiol and tetrahydrocannabivarin on glycemic and lipid parameters in patients with type 2 diabetes: a randomized, doubleblind, placebo-controlled, parallel group pilot study. Diabetes Care 39(10):1777. https://doi.org/10.2337/dc16-0650

129. Thapa D, Cairns EA, Szczesniak A-M, Kulkarni PM, Straiker AJ, Thakur GA, Kelly ME (2020) Allosteric cannabinoid receptor 1 (CB1) ligands reduce ocular pain and inflammation. Molecules 25(2):417 
130. Palmieri B, Laurino C, Vadalà M (2019) A therapeutic effect of cbd-enriched ointment in inflammatory skin diseases and cutaneous scars. Clin Ter 170(2):e93-e99

131. Koppel BS, Brust JCM, Fife T, Bronstein J, Youssof S, Gronseth G, Gloss D (2014) Systematic review: efficacy and safety of medical marijuana in selected neurologic disorders. Neurology 82(17): 1556-1563. https://doi.org/10.1212/wnl.0000000000000363

132. Kogan NM, Mechoulam R (2007) Cannabinoids in health and disease. Dialogues Clin Neurosci 9(4):413-430

133. Eubanks LM, Rogers CJ, Beuscher AE, Koob GF, Olson AJ, Dickerson TJ, Janda KD (2006) A molecular link between the active component of marijuana and Alzheimer's disease pathology. Mol Pharm 3(6):773-777. https://doi.org/10.1021/ mp060066m

134. Carroll CB, Bain PG, Teare L, Liu X, Joint C, Wroath C, Parkin SG, Fox P et al (2004) Cannabis for dyskinesia in Parkinson disease. A randomized double-blind crossover study. 63(7):12451250. https://doi.org/10.1212/01.wnl.0000140288.48796.8e

135. Gertsch J, Schoop R, Kuenzle U, Suter A (2004) Echinacea alkylamides modulate TNF- $\alpha$ gene expression via cannabinoid receptor $\mathrm{CB} 2$ and multiple signal transduction pathways. FEBS Lett 577(3):563-569

136. Raduner S, Majewska A, Chen J-Z, Xie X-Q, Hamon J, Faller B, Altmann K-H, Gertsch J (2006) Alkylamides from Echinacea are a new class of cannabinomimetics Cannabinoid type 2 receptordependent and-independent immunomodulatory effects. J Biol Chem 281(20):14192-14206

137. Woelkart K, Salo-Ahen OM, Bauer R (2008) CB receptor ligands from plants. Curr Top Med Chem 8(3):173-186
138. Battista N, Fezza F, Finazzi-Agro A, Maccarrone M (2006) The endocannabinoid system in neurodegeneration. Ital J Biochem 55(3-4):283-289

139. Souza ID, Hantao LW, Queiroz MEC (2019) Polymeric ionic liquid open tubular capillary column for on-line in-tube SPME coupled with UHPLC-MS/MS to determine endocannabinoids in plasma samples. Anal Chim Acta 1045:108-116

140. Tuccinardi T, Ferrarini PL, Manera C, Ortore G, Saccomanni G, Martinelli A (2006) Cannabinoid CB2/CB1 selectivity. receptor modeling and automated docking analysis. J Med Chem 49(3): 984-994. https://doi.org/10.1021/jm050875u

141. Montero C, Campillo NE, Goya P, Páez JA (2005) Homology models of the cannabinoid CB1 and CB2 receptors. A docking analysis study. Eur J Med Chem 40(1):75-83

142. Wang H, Duffy RA, Boykow GC, Chackalamannil S, Madison VS (2008) Identification of novel cannabinoid CB1 receptor antagonists by using virtual screening with a pharmacophore model. J Med Chem 51(8):2439-2446

143. Poso A, Huffman J (2008) Targeting the cannabinoid CB2 receptor: modelling and structural determinants of $\mathrm{CB} 2$ selective ligands. Br J Pharmacol 153(2):335-346

144. Song Z-H, Slowey C-A, Hurst DP, Reggio PH (1999) The difference between the $\mathrm{CB} 1$ and $\mathrm{CB} 2$ cannabinoid receptors at position 5.46 is crucial for the selectivity of WIN55212-2 for CB2. Mol Pharmacol 56(4):834-840

Publisher's Note Springer Nature remains neutral with regard to jurisdictional claims in published maps and institutional affiliations. 